\title{
'Multi Is My Culture': \\ Critical Reflections on Multicultural Arts in Tropical Australia
}

\author{
Hurriyet Babacan
}

\author{
Director, The Cairns Institute, James Cook University
}

\begin{abstract}
Australia is known as a multicultural country with over 40 percent of its population being either an immigrant or the child of an immigrant. Tropical Australia is unique in its landscapes, psyches and cultures. It is also a place of cultural diversity, with some areas where people of culturally and linguistically diverse backgrounds make up to 15 percent of the population. When people migrate, they bring along their cultures- reflected in language, poetry, music, fine arts and other creative mediums. The settlement process of immigrants in complex and multidimensional. The transplantation of multicultural arts in host society poses challenges and opportunities. This paper explores some of the key issues in multicultural arts in Tropical Australia. Particularly the policy context, recognition and display of multicultural art and role of artists in communities will be examined.
\end{abstract}

\section{Introduction}

Cultural expressions by minorities have gained international recognition over the last two $\checkmark$ decades. UNESCO's Convention on the Protection and Promotion of Diversity of Cultural Expression states that:

Parties shall endeavour to create in their territory an environment which encourages individuals and social groups: (a) to create, produce, disseminate, distribute and have access to their own cultural expressions, paying due attention to the special circumstances and needs of women as well as various social groups, including persons belonging to minorities and indigenous peoples (UNESCO, article 7.1).

The Convention also urges parties to recognise the important contribution of artists, others involved in the creative process, cultural communities, and organisations that support their work, and their central role in nurturing the diversity of cultural expressions.

Australia is known as a multicultural country with over 40 percent of its population being either an immigrant or the child of an immigrant. Tropical Australia (without entering into a debate about the geography of Australian Tropics) is unique in its landscapes, psyches and cultures. It is also a place of cultural diversity, with some areas where people of culturally and linguistically diverse backgrounds make up a significant percentage of the population. For example, the three states which comprise Tropical Australia are culturally diverse: in Queensland 17 percent of the state was overseas born, over 33 percent had one parent born overseas, in Northern Territory 14 
percent overseas born, in Western Australia 27 percent born overseas. Key cities of Tropical Australia are culturally diverse such as 22 percent of Darwin's and 17 percent of Cairn's population being born overseas (ABS, 2006). We also need to acknowledge that the Aboriginal and Torres Strait Islanders are also multicultural. However, we recognise Indigenous Australians as the original owners of Australia and have a distinct status as the First Nations Peoples and therefore, do not, include them with waves of immigrants who have come to Australia over the last 200 years.

When people migrate, they bring along their cultures which are reflected in language, poetry, music, fine arts and other creative mediums. The settlement process of immigrants is complex and multi-dimensional. The transplantation of multicultural arts in a host society poses challenges and opportunities. While the definition of culture can be broad to include different elements of life, it is often reduced to cultural forms made visible such as language, foods and art. Multiculturalism has been criticised since it has been played out in a way that it lends itself to 'cultural essentialism' and obscures historical, political, economic constructions of life. Moreover, contemporary forms of racism, called new racism, are based on 'culture' and cultural differences being insurmountable (Babacan et al 2009). A number of writers note that new racism now is often not demonstrated by direct acts of hostility but rather by more covert comments relating to moral character, alien cultural values and lifestyles (Pedersen et al. 2004; Fraser and Islam 2000) and is practiced without denouncing democratic principles.

The policy domain for multicultural Australia has changed over time. The phases can be broadly included as: pre-multicultural policy era of the White Australia Policy; bi-partisan support for multiculturalism from 1970s to late 1990s; and more recent questioning the benefits of multiculturalism. The current climate for multiculturalism is somewhat an ambiguous one. On the one hand there is bi-partisan support for 'Multicultural Australia' by the Government and the Opposition- at least at a rhetorical level. On the other hand, there are wavering Government and Opposition responses to key issues relating to multiculturalism that confront the nation such as the rights of asylum seekers and the policy of detention and the targeting of particular communities in the fight against the war on terror. These policy articulations shifted in emphasis from access and equity, social justice, to more recent years to social cohesion and unity (Babacan \& Babacan 2007).

Paralleling these policy domains are policies for multicultural arts which also change with the prevailing philosophies of the government of the day. A most notable development has been the development of the commitment to multicultural Australia by the Australia Council for the Arts which has supported culturally diverse artists over a long period of time. This recognition has been at a number of levels including the creation of a broad environment in which to develop strong multicultural arts practice; political and promotional activity required to support multicultural arts practice, and building infrastructure. Despite recognition of the role of multicultural art and artists in our national creativity, the reality experienced by multicultural artists is diverse and the pathways to finding spaces in the national landscape to express creativity have not been easy. This paper explores some of the key issues in multicultural arts and provides insights from multicultural artists in Tropical Australia based on research conducted from 2007-2009. 


\section{Methodology}

The research was conducted between 2007-2009 as part of a broader study about sense of place and belonging across Tropical Australia. Eleven in-depth interviews were conducted with artists who identified as belonging to culturally diverse backgrounds. Four artists were born in Australia to parents born in a non-English speaking country while seven were born overseas. The artists were five women and six men. The artists lived in a range of cities including Darwin, Cairns, Townsville, Mackay, Broome and Port Hedland and covered a range of visual and performing art forms including music, dancing, traditional crafts, poetry and acting.

Interviews were conducted using open-ended and semi-structured questions. The research approached adopted was a constructionist approach which posits that social reality is constructed and made real through subjective meaning (Flick, 2009). Thus lives and experiences of artists were accepted as varied and could not fit into a single law-like research structure. The research also drew from ethnography, which involves immersion in the lives of the people being studied and the placing of phenomenon in their social and cultural context (Lewis, 2003). Ethnography is useful in understanding complex human societies facets of life such as culture, kinship, and relationships (LeCompte and Schensul, 2010). Vidich and Lyman (2000:38) note that Ethnography is 'born out of concern to understand the Other'.

The data collected was very rich and wide. A thematic approach to data analysis was undertaken. I noted my role as mediator, translator, traveller, organiser, and orchestrator of knowledge (Rosaldo, 1993) in this process.

\section{Findings}

This section provides a summary of the findings using the thematic approach. This paper provides the perspectives of multicultural artists. It is acknowledged that there are multiple perspectives and the views of the broader arts sector is not represented in these findings.

\section{Approach to Art}

All artists drew inspiration from their cultural backgrounds, made hybrid by the influence of being in Australia. The sources of inspiration were people, events, landscapes and social phenomena. There emerged a number of important factors in the artists' approach to their work including individual expression derived from being of culturally diverse background, balance between tradition and innovation and the need to contribute to building better futures. There was a need to be creative as a form of expression of identity - of self, community and society. This was linking with memory, history, lived experiences but also imagining of the future. Concepts of country, longing, belonging and inclusion played an important role for all artists in the study. A sense of old and new coming together was important and the majority of the artists acknowledged Indigenous presence as being vital in this. One third of the artists were concerned with continuity and change and preservation of cultural heritage was a major factor in their approach to art. Some artists pointed to the collective nature of creativity. They identified that while creativity can be individual in many cultures this took collective forms with families, clans 
or larger groups. The ownership of these art forms created collective intellectual property rights which were important to group identity. These artists identified the difficulty of communicating this to Australian arts institutions which were steeped in individual forms of artistic endeavour.

\section{Visibility of Art}

There was concern expressed by artists about making their work 'accessible' to the general public. Artists commented on differences in aesthetic sensibilities, difficulty of achieving emotional attachments to arts forms due to different cultural frames and discernment of audiences. Four artists stated that they would suppress or change the content of their art subject to gain acceptance either in elite art circles or more general public. Artists noted that representation of their art was problematic and not respected. Some saw that the value of art was linked with cultural consumption and the marketability of products. They felt this shifted emphasis from creativity to value associated with usefulness to the economy. Despite this, many were optimistic about their art and believed that with increased globalisation and the use of digital technologies they would be able to speak to wider audiences.

\section{Multicultural Art in 'the Mainstream'}

Multicultural themes in mainstream art were identified as being treated in a problematic way. As one artist stated "there is an imbalance in the cultural representation of our heritage and arts". Artists identified that it was difficult to be recognised by art/cultural institutions. Some felt that their art form was valued less if seen to be typically traditional or ethnic and this was not perceived as 'high level art' by art managers. The key challenges raised by artists in this study included their art form being recognised as having value, access to art spaces (e.g. galleries), cultural support and the struggle for accurate representation (e.g. accents in films). Almost all of the artists were very critical of the reduction of multicultural arts and creativity to a 'festival' mentality. While many saw a place for multicultural festivals as forms of art and building of community cultural capital they felt that it stereotyped and narrowed what can constitute culturally diverse art. Many were critical of short term 'celebratory' arts which stereotyped their art and the power to be deep or transformatory. A number of artists pointed to hidden forms of racism and exclusion from the arts industry. There was strong criticism about political and cultural judgements in the arts and about the way excellence in arts is judged. Many believed that this was derived from dominant cultural frameworks which resulted in the lack of funding and support for multicultural artists. Some felt that arts institutions were safeguarding particular positions and saw culturally diverse art forms as a threat or diminution of their art forms, particularly what was considered the more 'elite' art.

\section{Participation in 'the Arts'}

Artists identified that there was little support forthcoming for their artistic work and none could do it professionally nor earn a living from it. The lack of opportunity to be employed professionally as an artist was voiced by the majority of the participants in this study. For many in tropical Australia, they were so removed from large cities such as Melbourne and Sydney, they did not think there was any hope of gaining employment in an artistic sphere in regional centres. A significant number stated that they did not have enough information and knowledge 
about what support they could access such as funding or connections with arts institutions. A number of barriers were identified including lack of opportunity to exhibit or perform artistic work; a paucity of funding to develop new work; difficulty in reaching broader audiences; access to arts infrastructure such as spaces to rehearse, create, develop, and produce new work; and lack of knowledge and connection with artists from the broader community. The cost associated with engaging in their art practice was a key issue including their time, access to spaces and materials and costs of promotion. They identified the need to receive training, mentoring and guidance about how to progress their art forms, especially skills in running an enterprise or small business linked with artistic activity. A suggestion was made to establish a multicultural artist's network so that artists could support each other. This was also seen as an artistic development which would lead to improvement of their skills and innovation in their art form and the benefits gained by interdisciplinary and intercultural opportunities to engage with other artists. Some thought that projects which profiled multicultural artists, particularly in regional areas, would benefit them in building an artistic profile. They also identified the need for support to promote and market themselves or their art. A number of artists commented on arts infrastructure and wanted support to gain access to arts spaces (galleries, halls) and many noted the difficulty of being successful in getting funding to support their community. One artist from a new and emerging ethnic community stated that the funding was not only for him but would have helped the settlement and healing in their community. One participant stated that the 'potential of multicultural artists has not been fully maximised' for the benefit of Australian society and in building vibrant and resilient communities. Some suggested linking multicultural artists with community capacity building initiatives, refugee settlement programs and other community or industry projects. They also noted that multicultural art could be used to build local economies and the potential for incorporation into the cultural tourism initiatives.

\section{Discussion}

The findings of this study identified struggles for multicultural artists. These were both philosophical and practical issues. The approach to art and creativity is defined based on notions of excellence, quality, and aesthetics and the standards adopted for excellence in arts in Australia were seen as universal b. There is little consideration of the cultural value base of such assumptions as though these could be determined in a cultural, linguistic and social vacuum. Additionally, creativity is assumed to be individual and collective forms of artistic expression is treated as problematic.

The management of diversity is thus greatly influenced by what holds value for the majority of the population. Despite the rhetoric of multicultural arts systemic inequalities exist in cultural institutions which prevent access to and participation. In Tropical Australia, artists voiced the difficulties of having cultural diversity being valued. This goes to the heart of debates about inclusion and citizenship. This study showed that addressing participation in the arts for multicultural artist is strongly linked with social justice issues. Loss of status upon migration, reduction of income, racism and participation in civil society are key structural issues which artists are confronting. The new forms of cultural racism obscure patterns of difference and discrimination and hide art/'race'-art/power issues. 
Multicultural artists are important as they are cultural brokers. Multicultural arts offer the opportunity for cultural exchanges as Australia is increasingly influenced and transformed by the process of globalisation. While at the moment those processes are mediated via media or market their effects are limiting and narrow. Arts and creativity enable free flow of the imagination and encourage new forms of thinking and engagement across cultural boundaries. This needs to be a facilitated process. Hence, the need for cultural brokerage, a role distinct from art administrators. The Director of National Programs at the Smithsonian Institution, Dr Richard Kurin, states:

Cultural brokers empirically and interpretively study the culture to be presented, arrive at models of understanding, develop a particular form of representation from a repertoire of genres, and bring audiences and culture bearers together, so that cultural meaning can be translated and negotiated (Cited in Australia Council 2009:13).

Multicultural artists often act as cultural brokers, albeit not recognised at times. They enable creativity that spans the spectrum of tradition and innovation, the local and the global. It is vitally important to recognise the social value of multicultural arts and artists in Australian society, particularly in building social capital and in addressing difficult social issues.

Multicultural artists need support including professional development, promotion to mainstream audiences and appropriate marketing and access to cultural resources and institutions. While recognising the social value of multicultural artists, there is also economic value $\mathrm{s}$ for multicultural arts and there is a business case to be made, as is demonstrated by concepts such as creative cities. For the social and economic benefits of multicultural artists to flow to society, there is a strong need for the diversification of the sector's workforce and leadership through ensuring equitable participation of artists of culturally diverse backgrounds.

\section{Conclusion}

The new century offers exciting opportunities and challenges in Australia's presentation to itself and to the world as a diverse and vibrant nation. As we struggle to determine our national identity and place in the world we need to recognise the role our arts plays in determining and reflecting who we are to ourselves and globally. Multicultural arts offer multilayered and complex ways of seeing the world and challenge us to think more broadly. However, we need to ensure that multicultural arts are not stereotyped or narrowed. Cope et al (2003:11) invite us to take a broader redefinition of multicultural arts including artwork, undertaken by anyone, which represents or interrogates cultural pluralism or globalism, avant-garde art addressing pluralism and globalism, just as much as art that explicitly references culture-as-tradition; hybridity and cultural transformation as much as references to cultural origins or ethnic roots; and art that challenges the fundamentals of nationalism, or the unitary identity that is supposed to coincide with the geographical nation-state.

In Tropical Australia, in close proximity to the Asia-Pacific region, cultural diversity is an integral part of our being. We cannot afford not to take up the invitation to take a broader approach to multicultural arts and inclusive approaches to multicultural artists. 


\section{Works Cited}

ABS (2006) Census of Population and Housing, Australian Bureau of Statistics, Canberra, www.abs.gov.au

Australia Council for the Arts (2009) Adjust Your View, Developing Multicultural Audiences for the Arts, Sydney, Australia Council for the Arts publication, http://www.australiacouncil.gov.au I_data/assets/pdf_file/0017/73511/Adjust_Your_View_Toolkit_4April2010.pdf

Babacan H., \& Babacan A. (2007) New Racism and Fear: The Cronulla Riots and Racial Violence in Australia, Review of International Law and Politics, Vol. 3, No. 10 , pp.147-152.

Babacan H., Gopalkrishnan N., \& Babacan A. (2009) Situating Racism: the Local, National, and the Global, Cambridge, Cambridge Scholar's Press.

Cope B., Kalantzis M., Zigouras C. (2003) Multimedia, Multiculturalism and the Arts: A Discussion Paper from the Australia Council, The Australia Council for the Arts, Sydney.

Flick U. (2009) An Introduction to Qualitative Research, London, Sage Publications.

Fraser C. \& Islam M. (2000) Social Identification and Political Preferences for One Nation: The Role of Symbolic Racism, Australian Journal of Psychology, vol. 52 (3), pp. 131-7.

LeCompte M. D. \& Schensul J. J. (2010 Designing and Conducting Ethnographic Research: An Introduction, Lanham, AltaMira Press.

Lewis I. M. (2003) Social and Cultural Anthropology in Perspective, New Jersey, Transaction Publishers.

Lowe L. (1996) Imagining Los Angeles in the Production of Multiculturalism, in, ed. Avery F. Gordon and Christopher Newfield, Mapping Multi-Culturalism, Minneapolis: University Press of Minnesota Press, pp. 413-423.

Pedersen A., Beven J., Walker I., \& Griffiths B. (2004) Attitudes Towards Indigenous Australians: The Role of Empathy and Guilt, Journal of Community and Applied Social Psychology, vol. 14,pp. 233-49.

Rosaldo R. (1993) Culture and Truth: The Remaking of Social Analysis, Boston, Beacon Press.

UNESCO (2005) Convention on the Protection and Promotion of Diversity of Cultural

Expression, http://portal.unesco.org/en/ev.php-

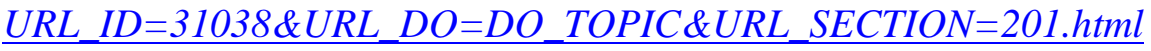

Vidich A. J. \& Lyman S.M (2000) Qualitative Methods: Their History in Sociology and Anthropology. In: Denzin, N. K. \& Lilcon, Y. S. (eds.) Handbook of Qualitative Research (2nd ed.). Thousand Oaks, Sage Publications. 